\title{
Buoyancy Driven Flow of Pseudoplastic Fluid Between an Outer Cylinder and Inner Grooved One.
}

Benhizia Oussama ( $\nabla$ benhizia_oussama@yahoo.fr)

University of Oran 2 Mohamed ben Ahmed https://orcid.org/0000-0002-7336-9664

\section{Bouzit Mohamed}

Faculty of Mechanical Engineering

\section{Original Article}

Keywords: Buoyancy induced flow, Boussinesq approximation, Cylindrical gap, grooves, Nusselt number, Pseudoplastic fluid.

Posted Date: October 25th, 2021

DOI: https://doi.org/10.21203/rs.3.rs-962671/v1

License: (1) This work is licensed under a Creative Commons Attribution 4.0 International License. Read Full License 


\title{
Buoyancy Driven Flow of Pseudoplastic Fluid between an Outer Cylinder and Inner Grooved One.
}

\author{
Benhizia Oussama $^{1 *}$, Bouzit Mohamed ${ }^{2}$ \\ ${ }^{1}$ Department of Electromechanic, Institute of Maintenance and Industrial Safety, University of Oran 2 Mohamed ben Ahmed, \\ Algeria \\ ${ }^{2}$ Laboratory of Science and Maritime Engineering, Faculty of Mechanical Engineering, USTO-MB, BP 1505, El-Menaouer, \\ Oran, 31000, Algeria
}

Corresponding Author Email: benhizia_oussama@yahoo.fr

https://doi.org/10.18280/ijht.xxxxxx

\section{Received:}

\section{Accepted:}

\section{Keywords:}

Buoyancy induced flow, Boussinesq approximation, Cylindrical gap, grooves, Nusselt number, Pseudoplastic fluid.

\begin{abstract}
This work examines the two-dimensional steady laminar natural convection of nonNewtonian fluid obeys the Ostwald-de Waele model in a gap between two concentric cylinders (the internal cylinder is grooved). The presence of grooves is of importance owing to their effectiveness in ameliorating the heat transfer of devices like micro-system, ICE (Internal Combustion Engine)....; Thus, we have conducted a numerical study for ranges of values Prandtl number $10 \leq \operatorname{Pr} \leq 10^{3}$, Rayleigh number $10^{3} \leq \mathrm{Ra} \leq 10^{5}$, power law index $0.4 \leq \mathrm{n} \leq 1$ and number of grooves 4, 8, 12 and 16 in this order, with the help of ANSYS-CFX 16.2. The finite volume method was used to discretize the governing equations and they solved by the SIMPLE algorithm.

It is to be said that the Nusselt number is proportional with Ra while it is disproportional with $\mathrm{n}$. Increasing the number of grooves drastically affects the heat transfer characteristics in the gap, by minimizing the surface that loses the heat between one groove and another, and therefore, the heat transfer is too small especially at the case of 16 grooves.
\end{abstract}

\section{INTRODUCTION}

In fluid mechanics, the buoyancy induced convection in fluid filled in a gap formed by two concentric cylinders represents a classical problem because of its increasing interest in engineering.

In the industry and manufacture, studying the fluid flow and heat transfer performance in solar collectors, nuclear reactors and heat exchangers is essentially to optimize their efficiency; For that reason, Numerous experimental and numerical works were performed in the last few decades using viscoelastic and inelastic non-Newtonian fluids [1-8]. Tetsu Fujii et al [9] used the sutterby model to study the natural convection of non-Newtonian fluid in an isothermal vertical cavity. They developed a correlation for the local Nusselt number using the Grashof and Prandtl numbers, and the sutterby parameters $\mathrm{A}$ and $\mathrm{Z}_{0}$, the profiles of temperature and velocity aren't found to be identical to those of the power law model.

Moses L. Ng \& J.P. Hartnett [10] found a new correlation for the Nusselt number introducing Prandtl, Grashof numbers and the power law index $\mathrm{n}$. They proved that the $\mathrm{Nu}$ number is autonomous of the $\operatorname{Pr}$ number in the laminar regime; Though, this latter one in the transient regime postpones the undershoot point where the transient Nusselt starts until it disappears at high Prandtl numbers [11]. K.G.T. Hollands et al [12] conducted a laboratory work on the free convection in a cube with differentially heated vertical walls at angles of $0^{\circ}, 45^{\circ}$ and $90^{\circ}$. They figured out that the errors between the experiment and the numerical solution is too small due to the fact that the CFD code doesn't take into consideration the variation of fluid properties with temperature; On the other hand, the experimental work which deals with the rhological effect of the non-Newtonian property $n$ on the heat flux was done by J.F.T. Pittman et al [13].

M. Ohta et al [14] conducted a numerical study of pseudoplastic fluid in the case of free convection using the sutterby model. They proved that the flow field is dependent on the pseudoplastic property, when this latter is very high it causes the flow to become such a complicated flow field. M.H. Park \& D.H. Ryu [15], H. Inaba et al [16] conducted an experimental study of microemulsion slurry in different rectangular enclosures' aspect ratios (width/height). They varied the mass concentration of it from $5 \%$ to $30 \%$ at three temperature ranges of phase-change-material (PCM) solid, liquid and phase changing cases and Rayleigh number $300 \leq \mathrm{Ra} \leq 10^{7}$. They found out that the natural convection and the heat transfer characteristics are affected by the previous parameters.

Lamsaadi et al [17-19] conducted series of analytical and numerical studies on the two dimensional steady state natural convection of power law fluid in a rectangular cavity in two cases: the first when its bottom part was heated and the second case: when it was submitted to uniform fluxes along both its short vertical sides. They found out that the temperature, streamline patterns and heat transfer are more sensitive to the power law behavior than the Newtonian fluids. L. Khezzar et al [20] added the effect of the cavity inclination angle $\left(0^{\circ} \leq \phi \leq 90^{\circ}\right)$ on the average Nusselt number and they found out that there is a peak angle where the heat 
transfer rate is maximum, this angle changes every time with the parameters $\mathrm{Pr}, \mathrm{Ra}$ and AR of the cavity.

W.L. Barth \& G.F. Carey [21] carried a comparison between the numerical and the experimental studies on the natural convection of Newtonian and non-Newtonian fluids. The effect of temperature dependent property on the viscosity of non-Newtonian fluids can be explained by the critical Rayleigh number when the conduction mode overcome in the numerical domain [22,23]. R.J. Poole \& B.S. Ridley [24] carried out a numerical investigation of inelastic fluid in a pipe. They proposed a correlation for the length $\mathrm{X}_{\mathrm{D}} / \mathrm{D}$ for the range $0.4<n<1.5$ and $0<\operatorname{Re}<1000$. R.P. Bharti et al [25] investigated the effects of Prandtl number, Richardson number and the power law index $\mathrm{n}$ on the heat transfer inside a cylinder. They declared that the heat transfer characteristics are quite alike to those by the forced convection. Also, it is found that adding buoyancy enhances the rate of heat transfer by about $45 \%$. A.C. Rust \& N.J. Balmforth [26] studied the instability of viscoplastic fluid convection, this fluid is able to generate stable Newtonian state if the Rayleigh number is of order of $B^{2 / 3}$. B. Albaalbaki \& R.E. Khayat [27] studied the Bénard instability of Carreau-Bird non-Newtonian fluid. They demonstrated that the pseudoplastic fluids can convect in forms of rolls, squares and hexagons while the dilatant fluids can convect only in form of rolls.

O Turan et al [28-31] conducted benchmark studies on the laminar natural convection of power law fluids in square enclosures numerically. Such studies examined the effects of the different parameters on the fluid flow and the heat transfer characteristics. M.H. Matin \& W.A. Khan [32] investigated the effect of Prandtl number, Rayleigh number, power law index $\mathrm{n}$ on the buoyancy induced flow in a cylindrical annuli numerically. N. Zeraibi et al [33] used the mixed finite elements method to study the flow of thermodependent non Newtonian fluid in a gap between two rotating cylinders. They represented the influence of temperature on the flow structure and thermal field at various rotating velocities. Z. Alloui et al [34] reported numerical and analytical study of the onset of free convection in a superficial enclosure filled with power law fluid for different hydrodynamic boundary conditions. They demonstrated that the onset of convection in pseudoplastic fluids is subcritical while it is supercritical in dilatant fluids at the same conditions. I. Pop et al [35] dealt with the problem of natural convection of power law fluid between two concentric and eccentric square channels. A new correlation for the Nusselt number in this geometry was found and discussed. In square cross-sectioned cylindrical annular cavity, N. Chakraborty et al [36] studied the laminar natural convection of power law fluid for the parameters $10^{3} \leq \mathrm{Ra} \leq 10^{6}, 10^{2} \leq \operatorname{Pr} \leq 10^{4}$ and $0.6 \leq \mathrm{n} \leq 1.8$. They proved that the velocity of dilatant fluids is lower than those of the Newtonian and pseudoplastic fluids; Also, the isotherm lines are parallel distributed for dilatant fluids but non uniformally distributed for pseudoplastic fluids which indicates that the heat transfer is large herein. K.M. Gangawane \& B. Manikandan [37] studied the two dimensional natural convection of power law fluid in a cavity includes hexagonal block and heated by it. The influence of power law index n, Colburn factor, Grashof and Prandtl numbers on the isotherms, streamlines and the Nusselt number are discussed.

Based on the above survey, using the non-Newtonian fluids in industries is essential. We aim to simulate a buoyancy induced flow in a gap between external cylinder and internal grooved one numerically. The attitude of the flow at shear thinning property is such a new evolution in this type of geometries. The effects of the previous parameters on the Nusselt number and the map of isotherms and streamlines are detailed.

\section{PROBLEM DEFINITION}

The current problem is schematically shown in figure 1 and considered as laminar two-dimensional steady state. The cylinders are supposed to be concentric and have constant temperatures with the internal cylinder $\mathrm{T}_{\mathrm{h}}$ is hotter than the external one $T_{c}\left(T_{h}>T_{c}\right)$ and the walls are taken as non-slip boundary conditions. The working fluid in the gap is supposed to be non-Newtonian Ostwald-de Waele fluid. The difference of temperatures between the two cylinders produces a buoyant flow which is employed by the Boussinesq assumption.

This model takes the density as a constant value in all equation terms, except for the buoyancy term in the momentum equation: $\left(\rho-\rho_{0}\right) g=-\rho_{0} \beta\left(T-T_{0}\right) g$

Where $\rho_{0}$ is the reference density, $\mathrm{T}_{0}$ is the operating temperature. Eq. (1) can be simplified as

$$
\rho=\rho_{0}(1-\beta \Delta T)
$$

This approximation is accurate as long as changes in actual density are small; specifically, it is valid when $\beta\left(\mathrm{T}-\mathrm{T}_{0}\right)<<1$.

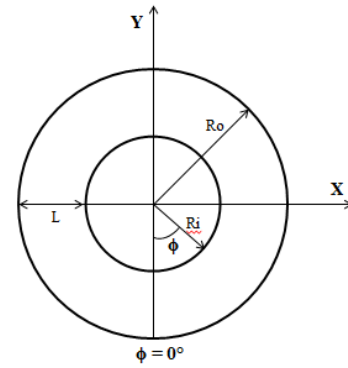

a)

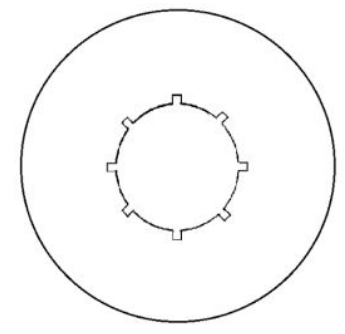

b)

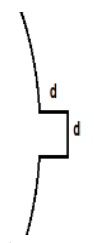

c)
Figure 1. Representation of the problem

a) Smooth cylinder, b) Grooved cylinder, c) Groove shape

The solution governing equations may be written as :

$$
\begin{gathered}
\frac{\partial u}{\partial x}+\frac{\partial v}{\partial y}=0 \\
\rho u \frac{\partial u}{\partial x}+\rho v \frac{\partial u}{\partial y}=-\frac{\partial P}{\partial x}+\mu\left(\frac{\partial^{2} u}{\partial x^{2}}+\frac{\partial^{2} u}{\partial y^{2}}\right) \\
\rho u \frac{\partial v}{\partial x}+\rho v \frac{\partial v}{\partial y}=-\frac{\partial P}{\partial y}+\mu\left(\frac{\partial^{2} v}{\partial x^{2}}+\frac{\partial^{2} v}{\partial y^{2}}\right)+\rho g \beta\left(T-T_{c}\right) \\
\rho C_{p} u \frac{\partial T}{\partial x}+\rho C_{p} v \frac{\partial T}{\partial y}=k\left(\frac{\partial^{2} T}{\partial x^{2}}+\frac{\partial^{2} T}{\partial y^{2}}\right)
\end{gathered}
$$

The Rayleigh and Prandtl numbers are

$$
\mathrm{Ra}_{\text {nom }}=\frac{\rho^{2} g \beta C_{p} \Delta T L^{3}}{\mu_{\text {nom }} k^{2}} \quad \operatorname{Pr}_{\text {nom }}=\frac{\mu_{\text {nom }} C_{p}}{k}
$$

The main difference between Newtonian and non-Newtonian fluids is essentially in the viscosity term, following the power law model in the cartesian coordinate, the relation between the stress tensor and the strain rate tensor might be written as : $T_{i j}=\mu_{a} e_{i j}=K\left(e_{k l} e_{k l} / 2\right)^{(n-1) / 2}$ 
In our study, the characteristic length $\mathrm{L}$ is defined as the substraction of the inner cylinder from that of the outer cylinder $\mathrm{L}=\mathrm{R}_{\mathrm{o}}-\mathrm{R}_{\mathrm{i}}$.

The nominal viscosity which was mentioned in eq. (7) is not a constant value over $\mathrm{L}$ as the other fluid properties are, so we will define it based on a characteristic shear rate $\gamma$ with $\gamma=u_{\text {char }} / \mathrm{L} . u_{\text {char }}$ is the characteristic velocity scale which is defined as a function of the parameters $\alpha$ and $\mathrm{L}$ as : $u_{\text {char }} \approx \alpha / \mathrm{L}$. The expression of $\mu_{\text {nom }}$ becomes :

$$
\mu_{\text {nom }} \approx K \gamma^{n-1} \approx K\left(\alpha / L^{2}\right)^{n-1}
$$

Nominal Rayleigh and Prandtl numbers become :

$$
\begin{array}{rrr}
\mathrm{Ra}_{\text {nom }}=\frac{\rho g \beta \Delta T L^{2 n+1}}{\alpha^{n} K} & \operatorname{Pr}_{\text {nom }}=\frac{K L^{2-2 n}}{\rho \alpha^{2-n}} \\
\text { suelt number is: } & \mathrm{Nu}=\frac{h L}{k}
\end{array}
$$

\section{VERIFICATION OF THE RESULTS}

To make it accurate, the simulations results in the present study have been compared with the values reported by M.H. Matin \& W.A. Khan [32] for Nusselt number versus Rayleigh number as shown in figure 2 and for the dimensionless temperature as shown in figure 3 . The agreement between our data and the data reported in M.H. Matin \& W.A. Khan [32] is excellent across all the entire angles.

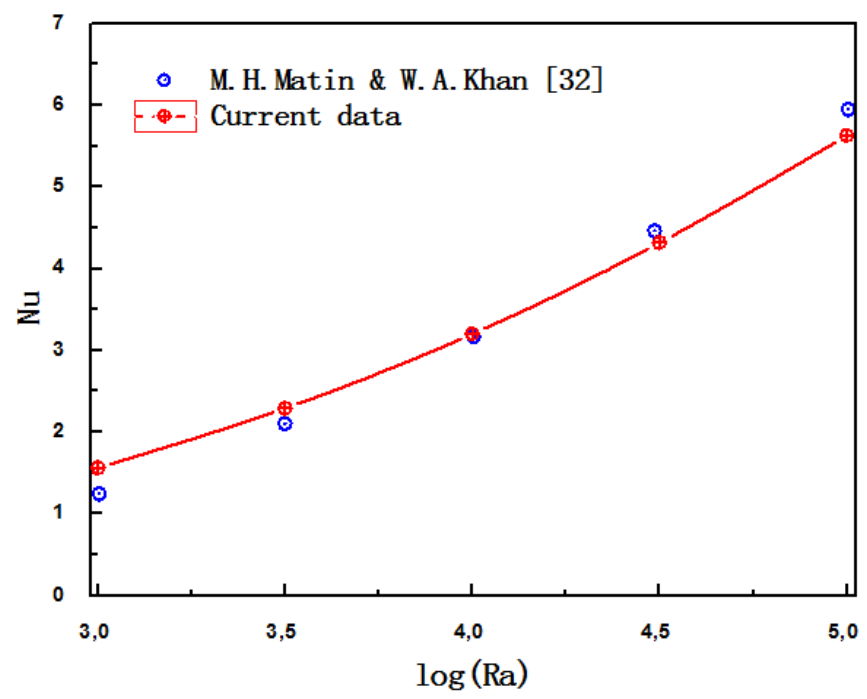

Figure 2. Comparison between the present results for the $\mathrm{Nu}$ number and the results reported by M.H. Matin $\&$ W.A. Khan [32] for smooth cylinder, $n=1, R R=2.5$ and $\operatorname{Pr}=0.7$

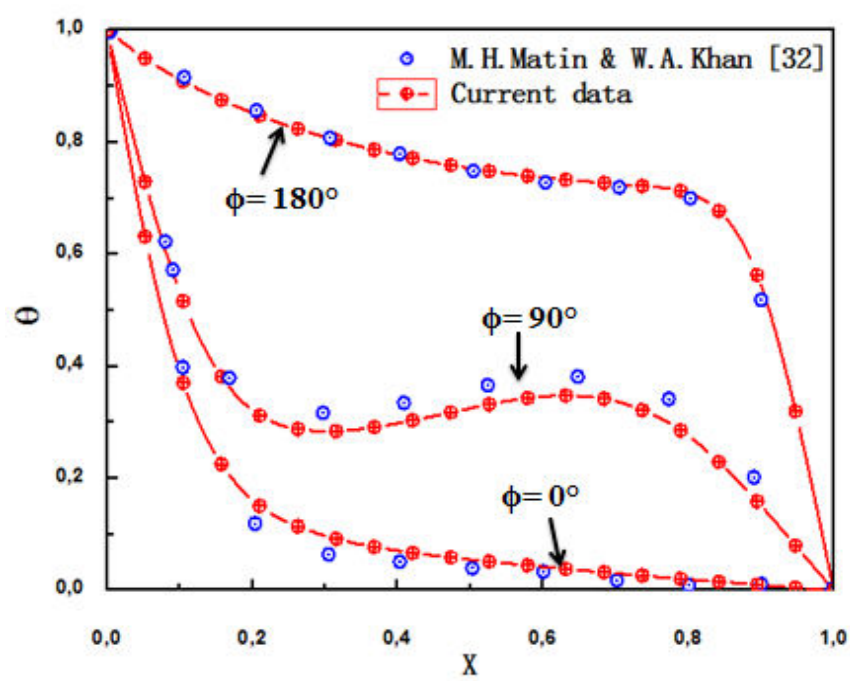

Figure 3. Comparison between the present results for the dimensionless temperature and the results reported

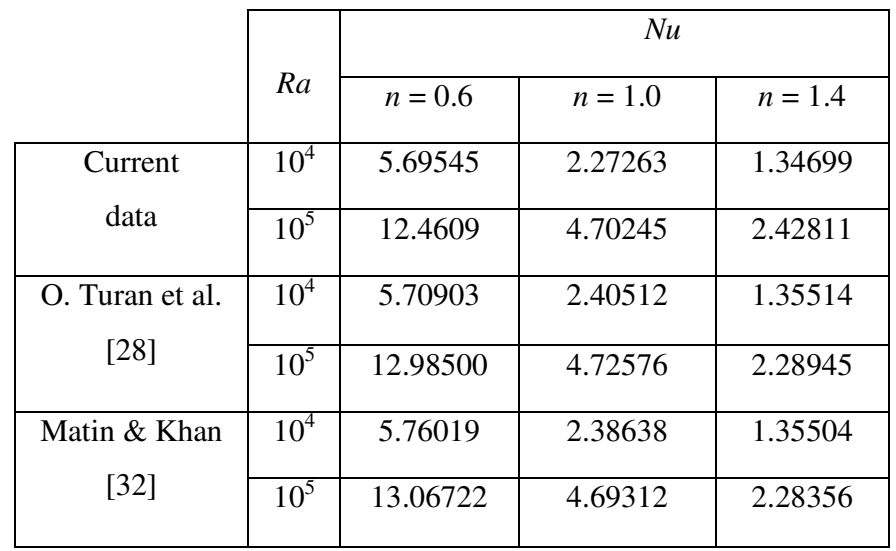

by M.H. Matin \& W.A. Khan [32] for smooth cylinder, $n=1, R R=2.6, \mathrm{Ra}=4.710^{4}$ and $\operatorname{Pr}=0.706$

As an additional benchmark comparision, the simulation results of our non-Newtonian fluid have been compared against the well-known benchmark data of O. Turan et al. [28] and M.H. Matin \& W.A. Khan [32] for Rayleigh number ranging from $10^{4}$ to $10^{5}$, power law index $0.6 \leq \mathrm{n} \leq 1.4$ and smooth cylinder. The comparisons between the present simulation results for non-Newtonian fluids with the corresponding benchmark values were found to be excellent as the table 1 illustrates.

Table 1. Comparison of the average Nusselt number between our work (Current data) and the results of O. Turan et al [28] and M.H. Matin \& W.A. Khan [32]

\section{DISCUSSIONS}

The streamlines in figure 4 are for pseudoplastic fluid and for flow of the power law indexes 0,4 and 0,8 at values of $\mathrm{Pr}=$ 100 and $\mathrm{Ra}=10000$. Natural convection begins when the cold fluid in the gap between the two concentric cylinders changes its direction from the hot inner cylinder to the cold outer cylinder. The lighter fluid exits through the upper part of the annular space.

It is noted that the lower the structural (flow) index $n$, the greater the flow intensity between $n=0.4$ and $n=0.8$, the maximum flow rate decreases by almost $80 \%$. For the same flow index the flow intensity is almost the same for all 
geometries except for the cylinder of 16 grooves where we notice a drastic reduction in the flow intensity, the maximum speed is reduced by $55 \%$ for $n=0,4$ and $84 \%$ for $n=0.8$.

It is evident that with a decrease in the flow index $n$, the vortices move upward to form a dense region in the upper part of the inner cylinder. This region shows that the movement of the fluid and then the convection transport become stronger for the more fluidifying fluids, for the cylinder of 16 grooves, the vortex remains in the middle especially for $\mathrm{n}>0,4$, which reduces the flow intensity and thus the reduction of convection transfer.

Figure 5 shows the influence of the presence of grooves on the flow structure. We notice that the fluid contact surface with the inner cylinder is reduced due to cavities between the grooves. For the cylinders of 4,8 and 12 grooves, the influence is not very important because the main flow penetrates deep into the space between the grooves, but for the cylinder of 16 grooves, the upward flow affects practically only the top surface of the grooves, the size of the cavities between the grooves is too small that the recirculation prevents the contact of the cold fluid with the bottom surface between these grooves.

Figure 6 shows the isotherms for the different geometries and for flow indices $0.4,0.8$ and 1 . With increasing the flow index $\mathrm{n}$, there is a reduction in the transfer rate. When the flow index $\mathrm{n}$ is small the thermal gradient near the cylinders increases to increase the heat transfer rate. For the same flow index $n$, it can be said that the total heat transfer rate can be almost the same for the cylinders of 4,8 , and 12 grooves as for the smooth cylinder, but for the cylinder of 16 grooves, the plume region is not formed in the annular space especially for indices $n>0.4$ and the heat transfer for this geometry is small.

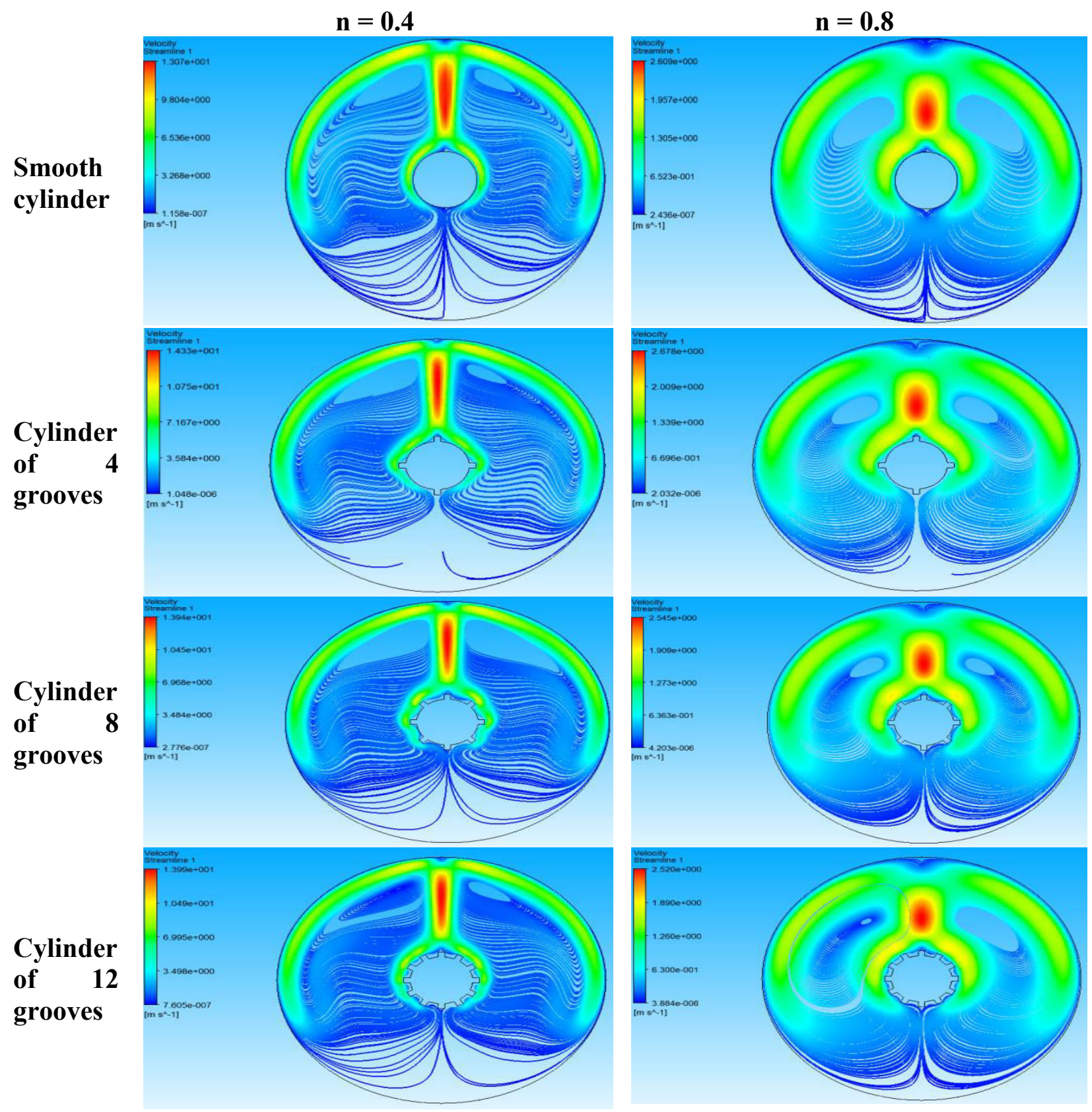




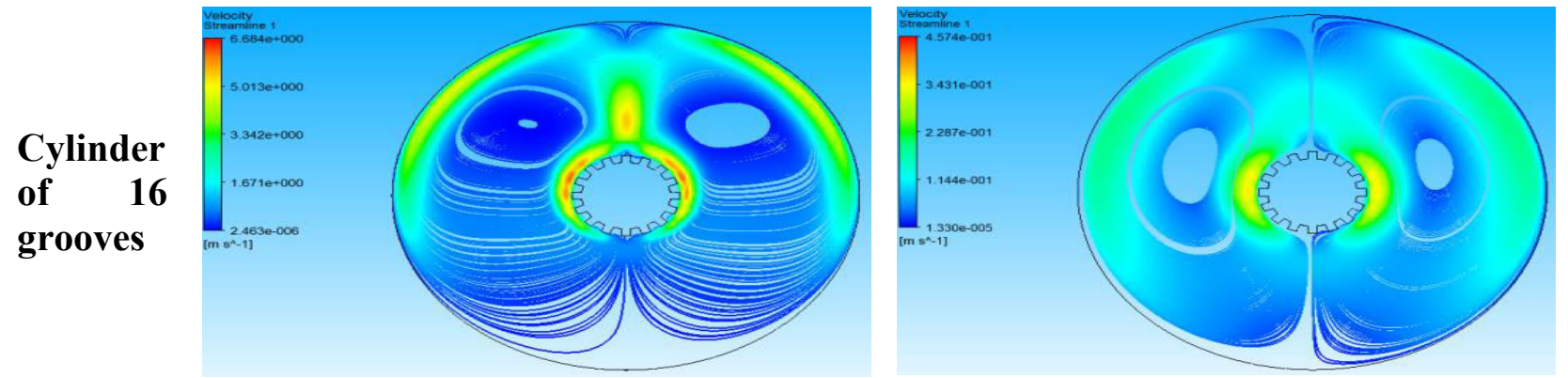

Figure 4. Streamlines for $\operatorname{Pr}=100$ and $\mathrm{Ra}=10^{4}$ for different geometries

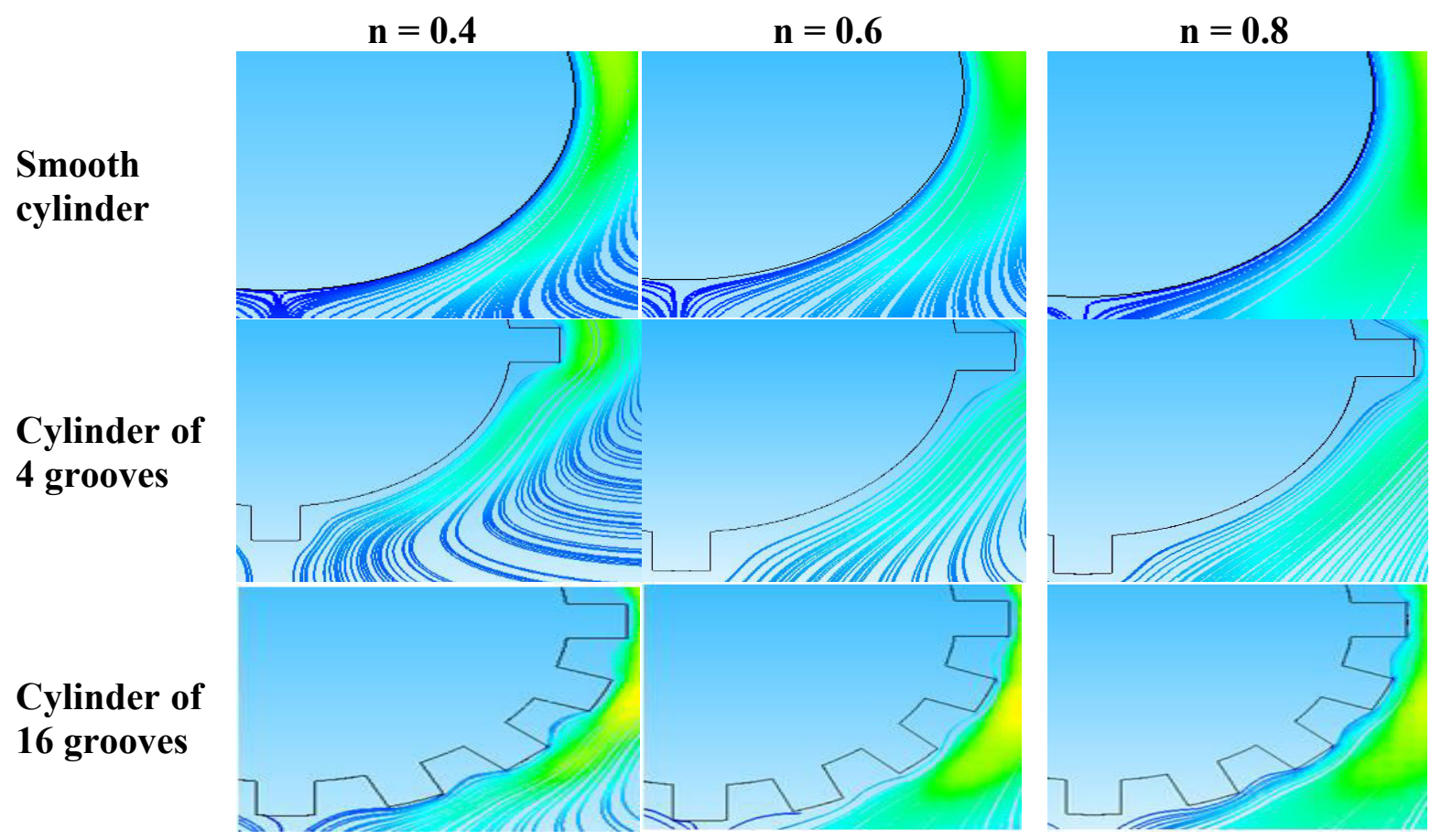

Figure 5. Streamlines for $\mathrm{Pr}=100$ and $\mathrm{Ra}=10^{4}$ for different geometries

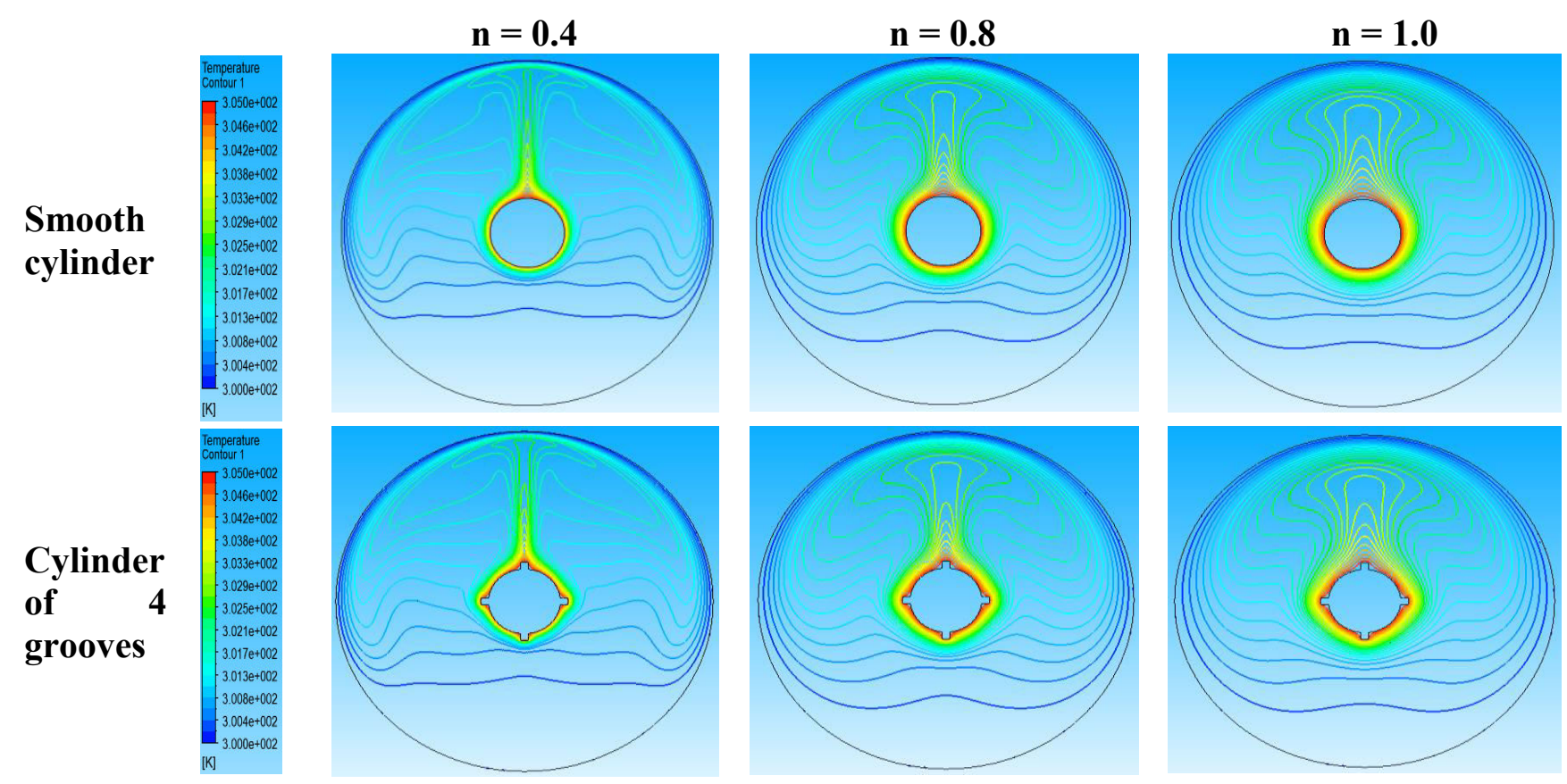




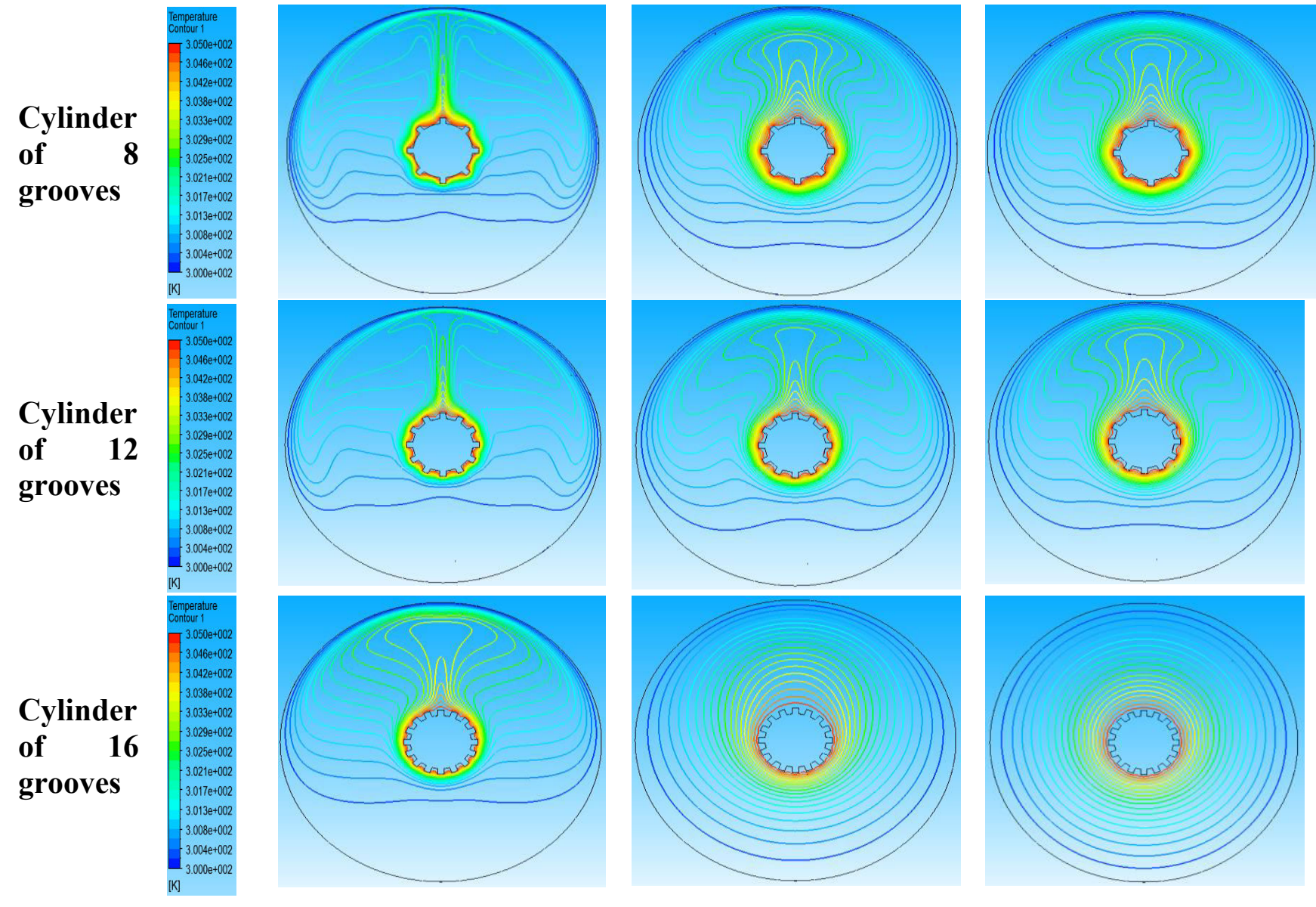

Figure 6. Isotherms for $\operatorname{Pr}=100$ and $\mathrm{Ra}=10^{4}$ for different geometries
$\mathrm{Ra}=10^{3}$
$\mathrm{Ra}=10^{4}$
$\mathrm{Ra}=10^{5}$

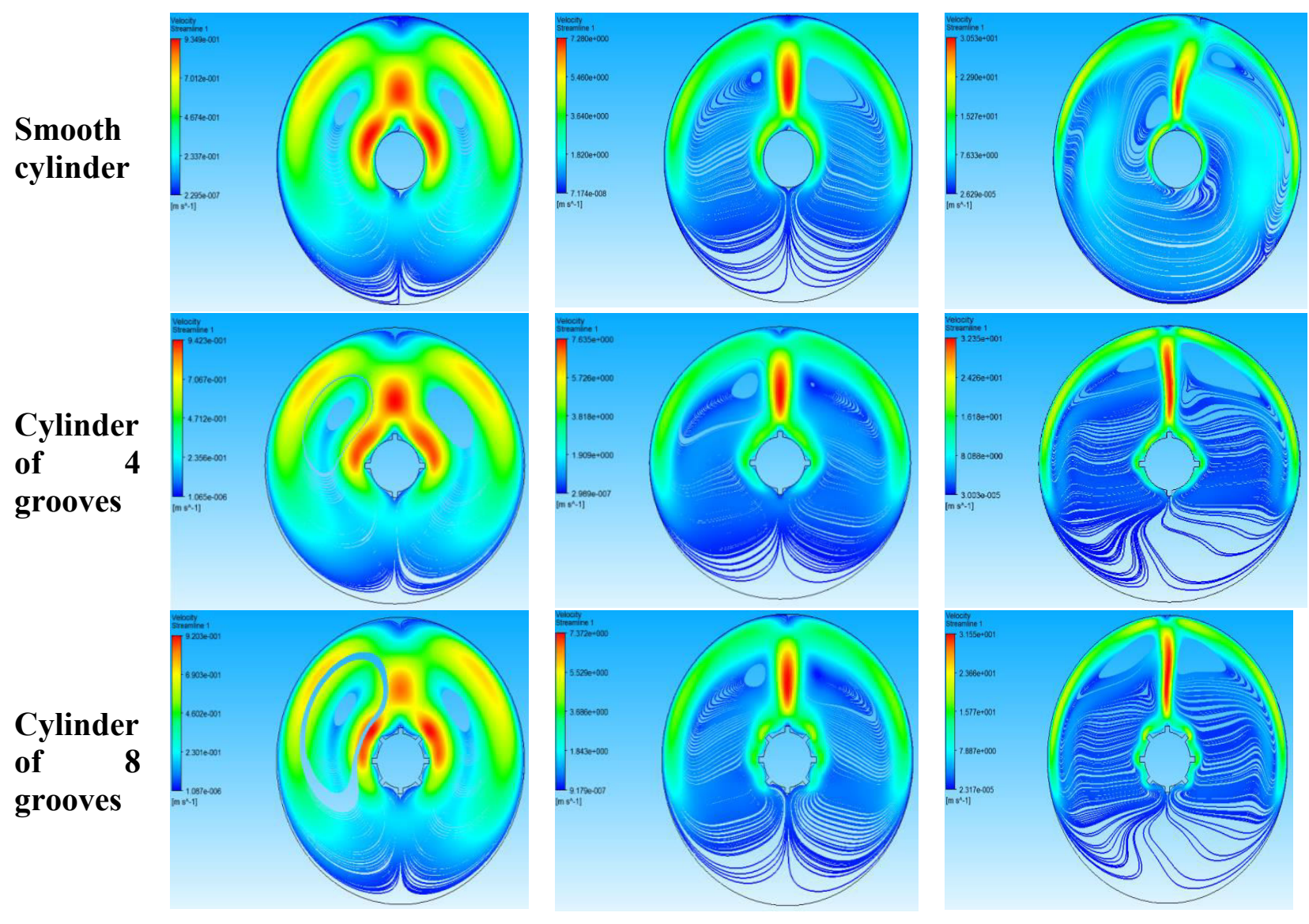




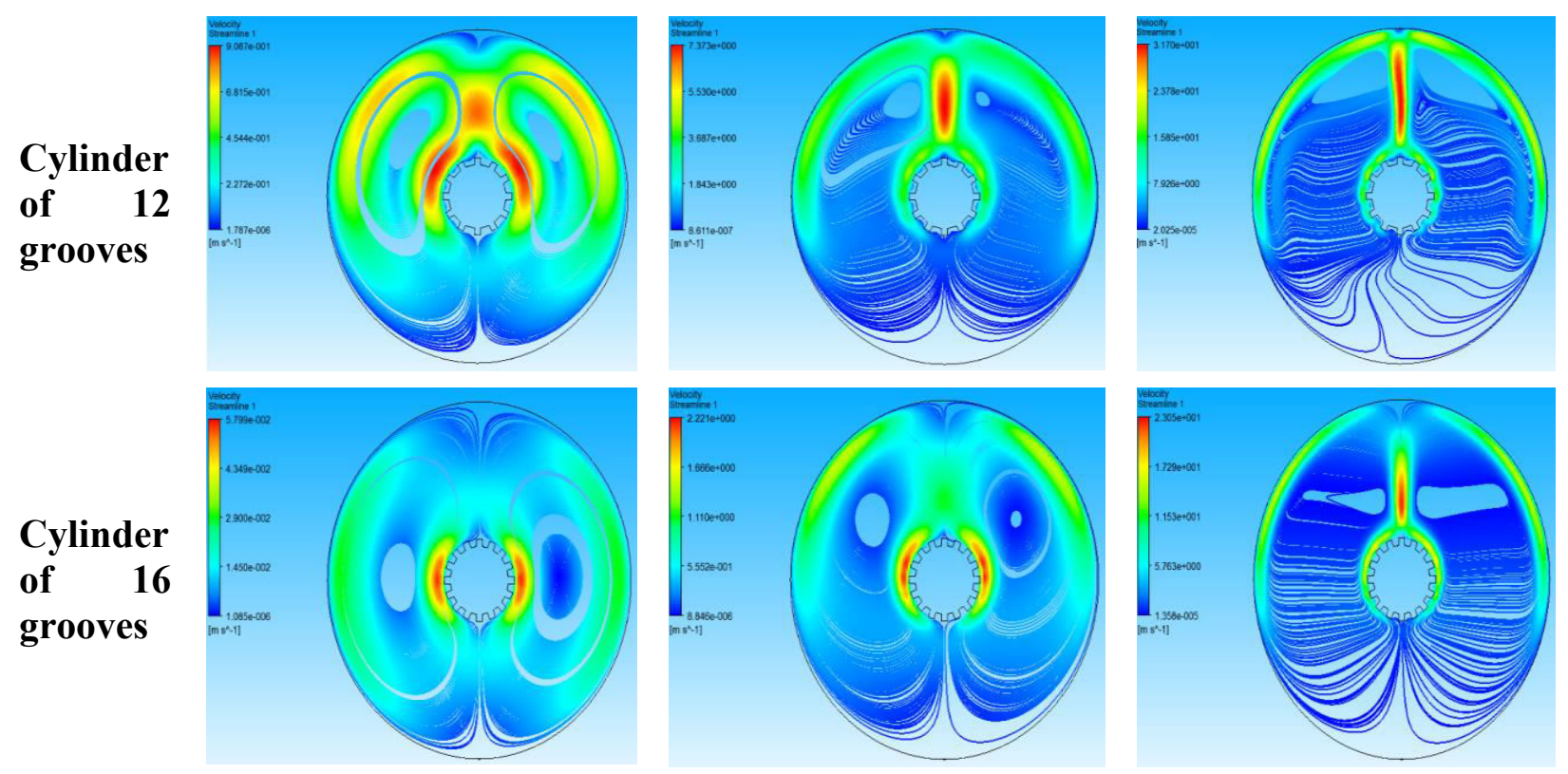

Figure 7. Streamlines for $\operatorname{Pr}=100$ and $n=0.6$ for various géometries

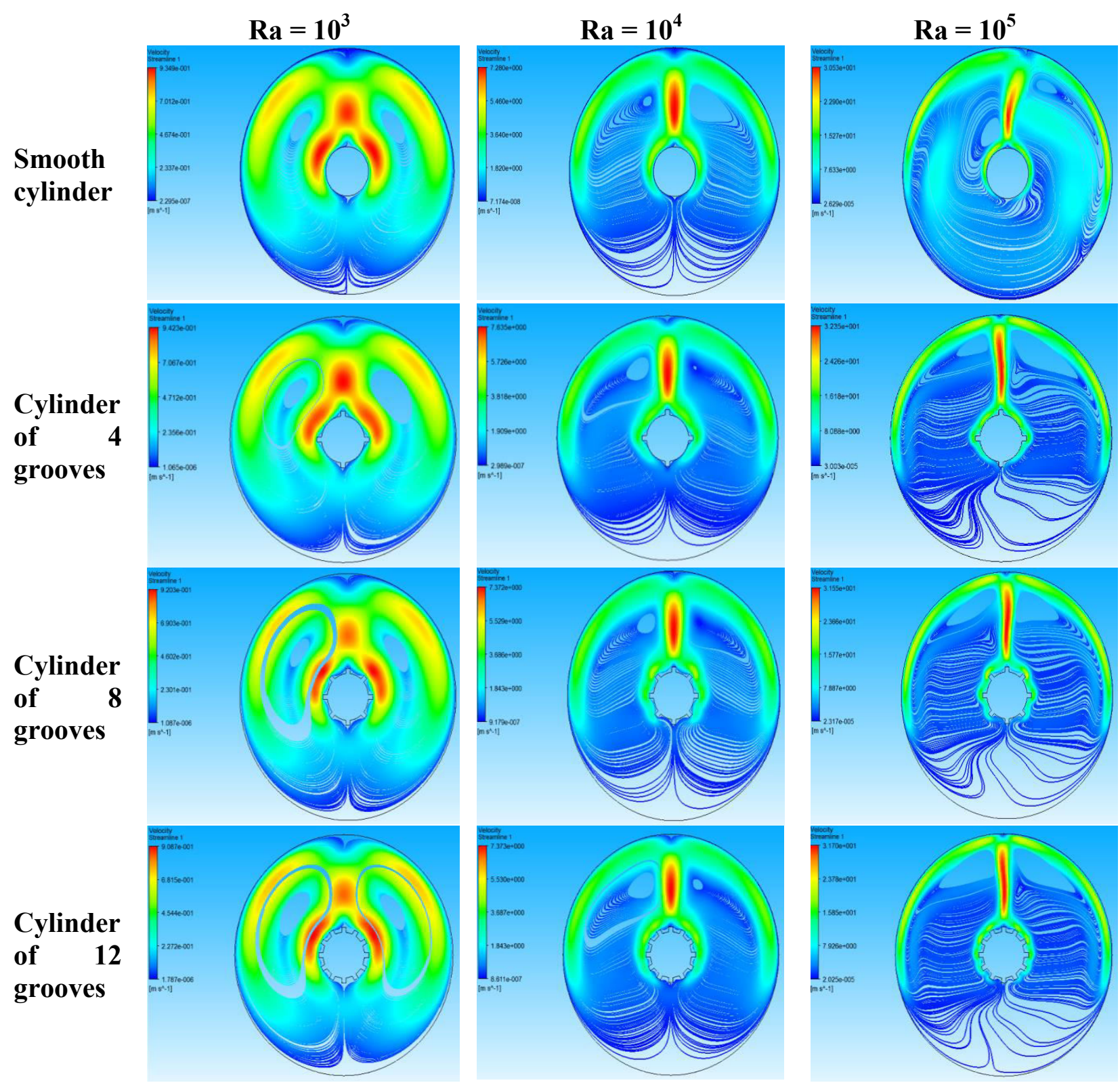




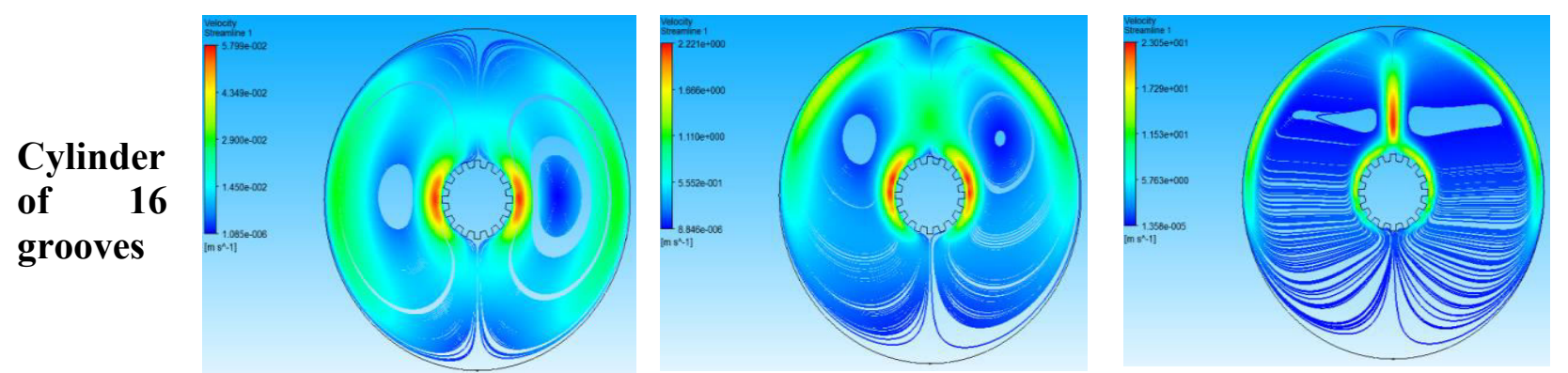

Figure 8. Streamlines for $\operatorname{Pr}=100$ and $\mathrm{n}=1$ for different geometries

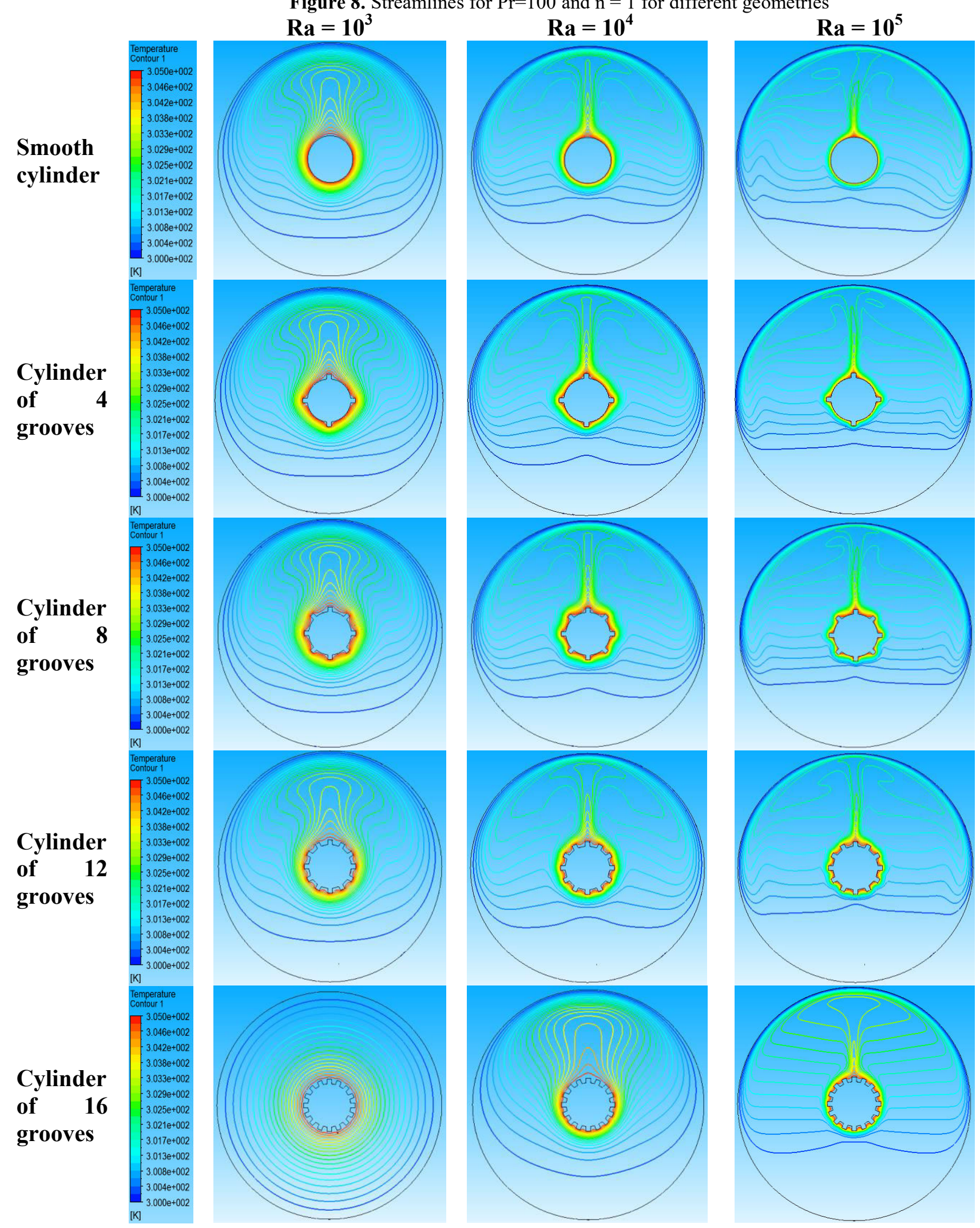


Figure 9. Isotherms for $\operatorname{Pr}=100$ and $n=0.6$ for different geometries

Figures 7 and 8 illustrate the effect of Rayleigh number on streamlines. The thermal gradient near the walls increases with the increase in the number of Rayleigh and this growing causes an increase in buoyancy, therefore the plume area enlarges. It can be seen that by increasing the number of Rayleigh the central vortex of the main tourbillon stretches and the center of the inner vortex moves upward due to the buoyancy effect. For the same flow index and the same number of Rayleigh the flow behaviour is almost the same for all geometries except for the cylinder of 16 grooves where we notice a low buoyancy for $10^{3} \leq \mathrm{Ra} \leq 10^{4}$. The flow is laminar for $\mathrm{Ra} \leq 10^{4}$, this flow becomes unstable when $\mathrm{Ra}$ reaches $10^{5}$. 
Line 1
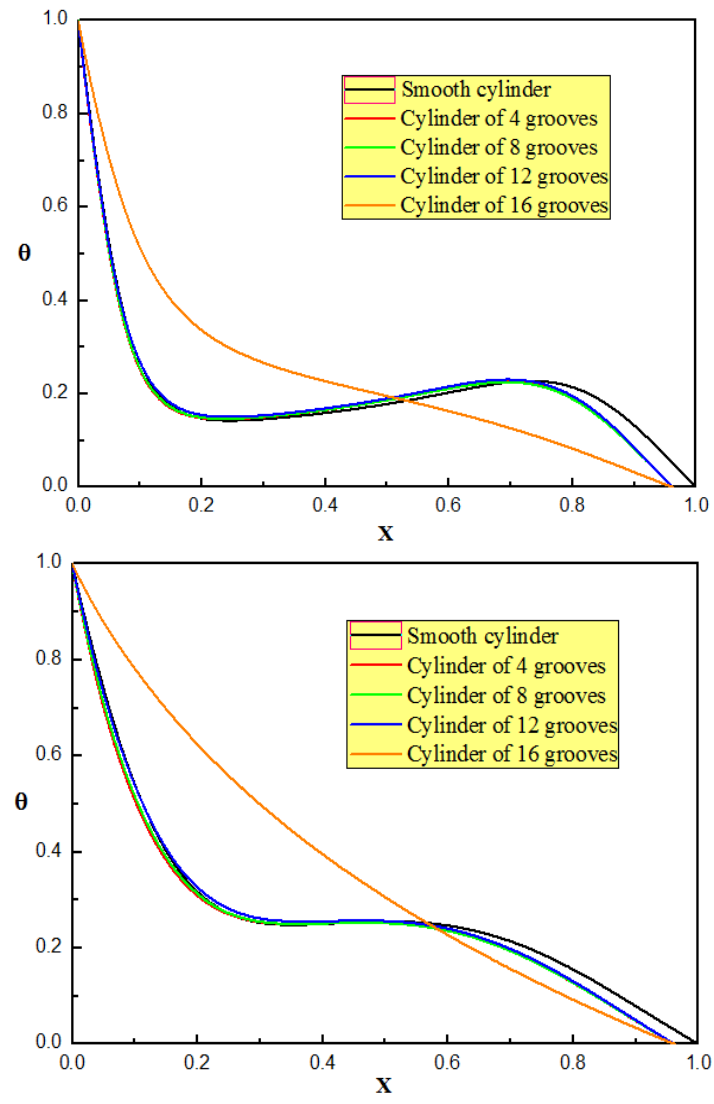

Line 2
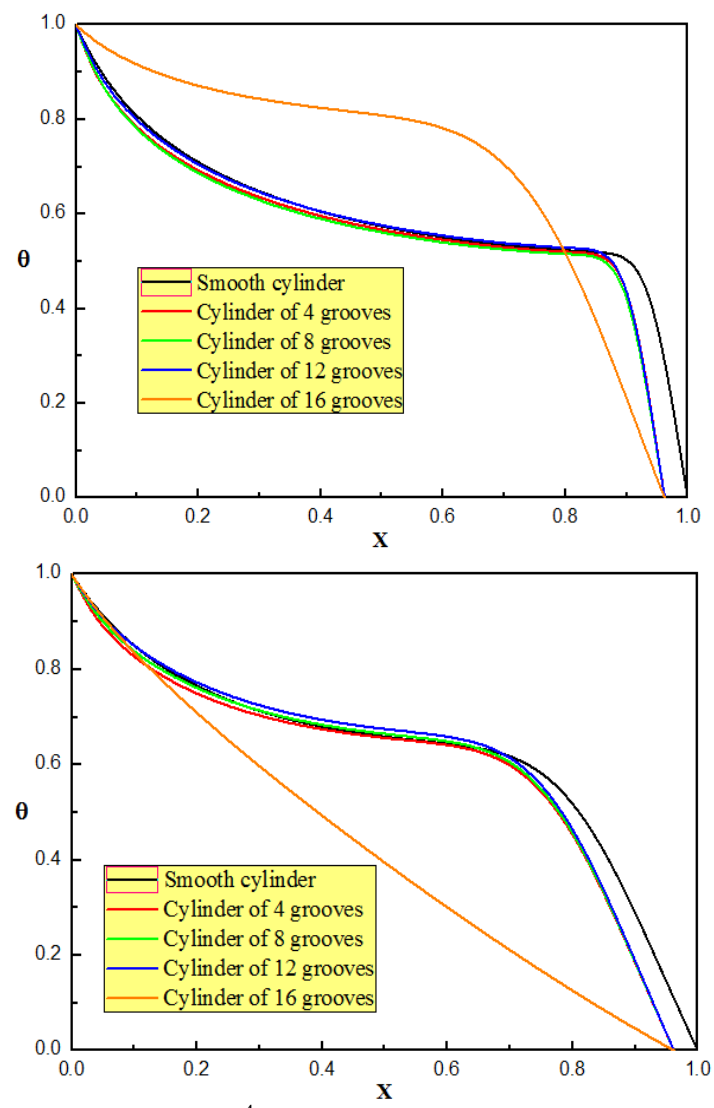

Figure 10. Dimensionless temperature along both lines 1 and 2 for $\operatorname{Pr}=10, \operatorname{Ra}=10^{4}$ and $n=0.6$ (first row), $n=1$ (second row)
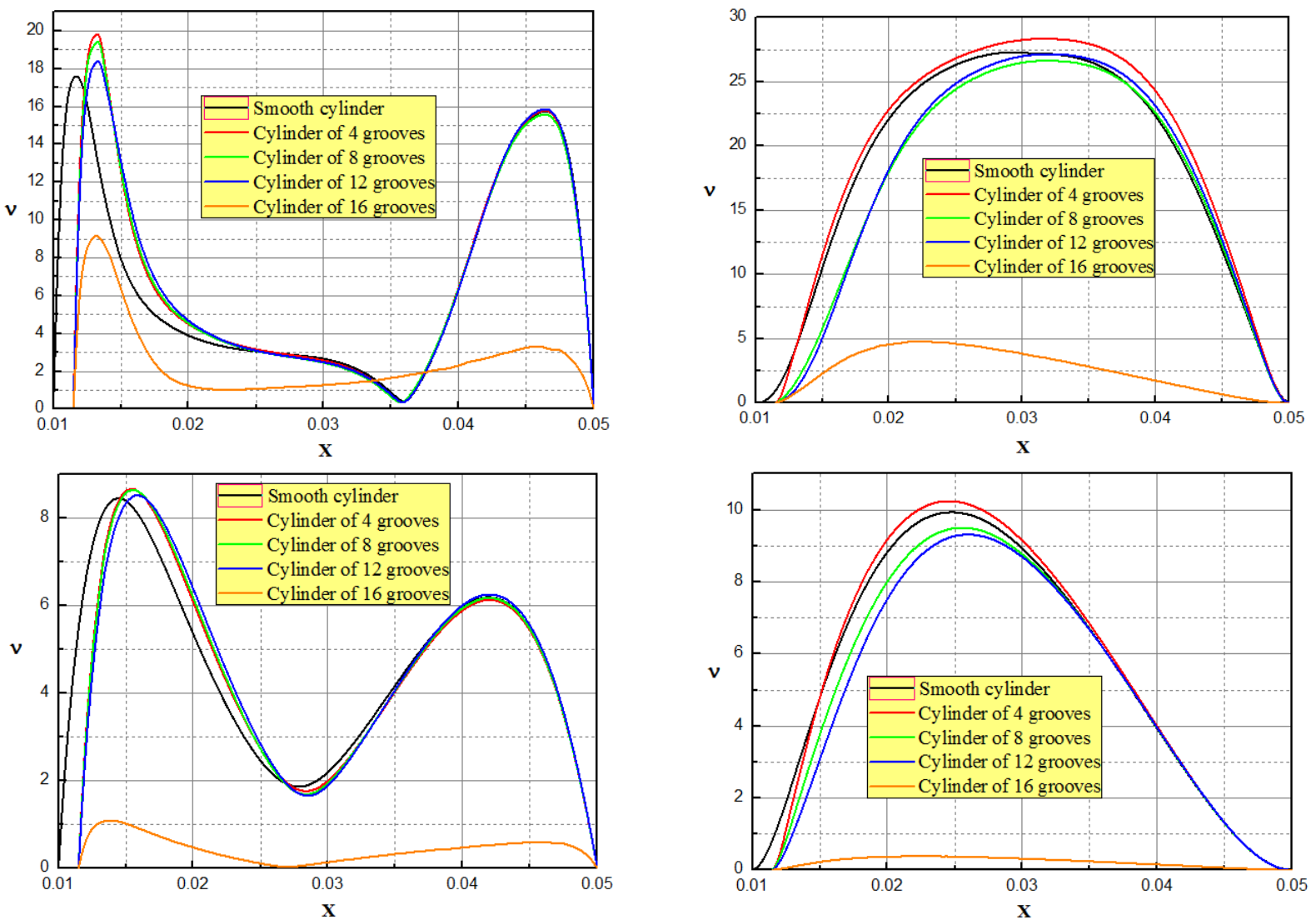

Figure 11. Velocity profiles along both lines 1 and 2 for $\operatorname{Pr}=10, \operatorname{Ra}=10^{4}$ and $n=0.6$ (first row), $n=1$ (second row) 
Figure 9 illustrates the effect of Rayleigh number on isotherms. The thermal gradient near the walls increases with the increase in the number of Rayleigh and this growing causes an increase in buoyancy, therefore the area of the thermal plume increases except for the cylinder of 16 grooves where there is no plume for $\mathrm{Ra}=10^{3}$ and starts to appear at $\mathrm{Ra}=10^{5}$. By increasing the flow index $\mathrm{n}$ the plume area appears only at important Rayleigh numbers (for Newtonian fluids $\mathrm{n}=1$ to $\mathrm{Ra}=10^{3}$ isotherms are concentric and the plume area doesn't exist).

Figure 10 and 11 clarify the variation of the dimensionless temperature and the velocity along both lines 1 and 2 (line 1 at angle of $90^{\circ}$ and line 2 at angle of $180^{\circ}$ ) for values of $\operatorname{Pr}=100$ and $\mathrm{Ra}=10^{4}$. It is evident that the temperature along the vertical line is greater than that in the horizontal line and that's because the hot fluid moves upward the inner cylinder and the cold one accumulated at the bottom (the thermal area is centralized at the top of the gap). Also, we notice that the flow index $\mathrm{n}$ affects the distribution of $\theta$, the distribution of $\theta$ along both lines is not linear for both fluids but for the Newtonian fluids it is more linear than pseudoplastic fluids. Finally, for the geometries of 4, 8, 12 grooves and smooth cylinder the curves of $\theta$ are almost congruous and this means that they have the same temerature distribution pattern while in the geometry of 16 grooves this curve is flat especially for flow index $n=1$ where the heat transfer mechanism is purely by conduction for $\mathrm{Ra} \leq 10^{4}$ as we've mentioned earlier.

For the velocity we notice that as the flow index $n$ increases the profiles of the velocity decrease along both lines and this refers to the impact of shear thinning behaviour on the velocity magnitude are more pronounced for pseudoplastic fluids than the Newtonian fluids (pseudoplastic fluids are more fluidizer and lighter than the Newtonians so the fluid recirculates rapidly in them and the viscous flow resistance is low in comparison with the Newtonian fluids). Also, it is remarked that there is a small difference between the viscosity values of the geometries for the cylinders of 4,8 , 12 grooves and smooth cylinder except for the cylinder of 16 grooves where the fluid movement is very slow, this effect is due to the weak buoyancy force in this geometry when Rayleigh has been taken at this value $\left(\mathrm{Ra}=10^{4}\right)$, this geometry can remarkably reduce the heat and acts as an insulator, generally convection begins to appear at $\mathrm{Ra}=10^{5}$.

Figure 12 represents the effects of Prandtl, Rayleigh numbers, grooves and flow index $\mathrm{n}$ on the heat transfer rate. We notice that the curves' trend of the Nusselt number descends as the flow index $n$ increases which means that the pseudoplastic fluids are able to transfer the heat better than the Newtonian fluids, so we can tell that the flow index $n$ enhances the Nusselt number. Secondly, the convective transport strengthens by increasing the Rayleigh number for the same set of values of $\operatorname{Pr}$ and $n$, when $\mathrm{Ra}$ is low $\left(\mathrm{Ra}=10^{3}\right)$ conduction is the dominant mode of heat transfer (the Nusselt number is very small), by increasing Ra convection starts to be the dominant mode of heat transfer and it is clearly seen in pseudoplastic fluids than the Newtonians (the curves of the Nusselt number for pseudoplastic fluids go up higher than the Newtonian fluids at the same set of Pr and $\mathrm{n}$ ). The Prandtl number doesn't affect the heat transfer in the gap for Newtonian fluids, this is due to the fact that its effects are more on the hydrodynamic boundary layer thickness than the thermal boundary layer thickness, for the case of pseudoplastic fluids $(\operatorname{Pr}<1)$ its effect appears to be more on the thermal boundary layer thickness.

The grooves effect seems to reduce the Nusselt number, each time we add 4 grooves the heat transfer diminishes regularly from the smooth cylinder to the cylinders of 4,8 and 12 grooves, respectively. But when it comes to the cylinder of 16 grooves there is a severe drop in the Nusselt number which means that its resistance is very high.
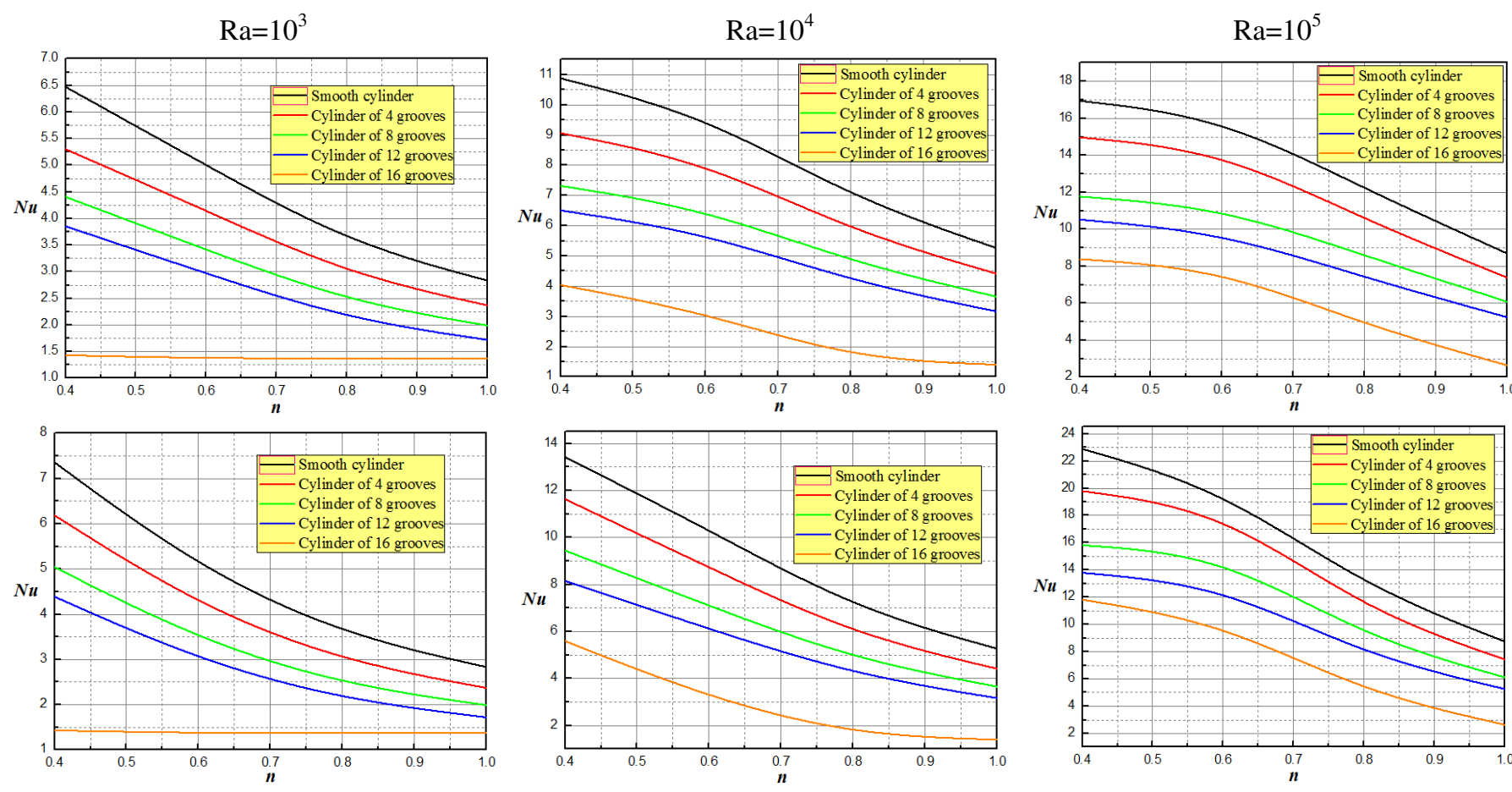

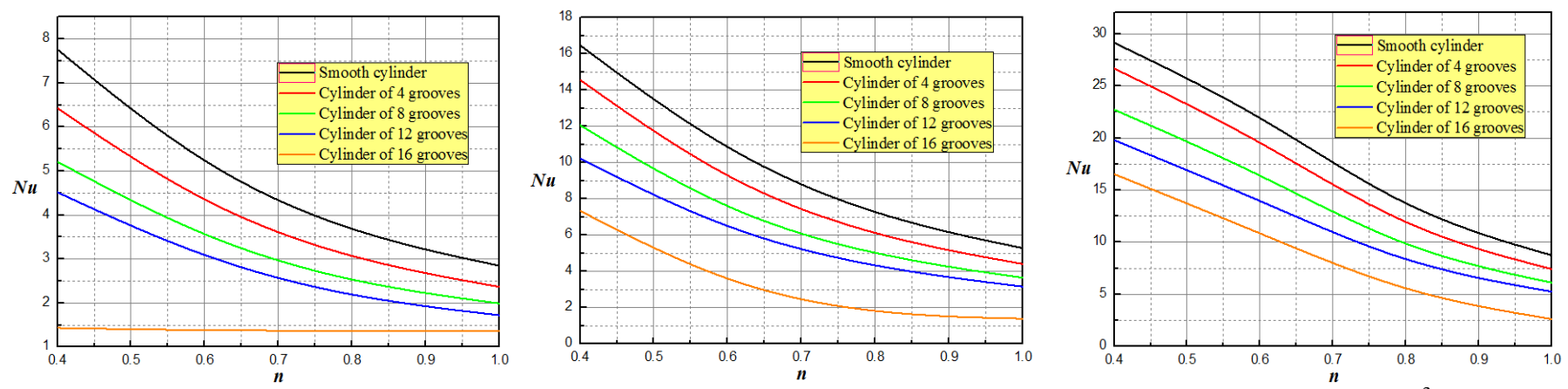

Figure 12. Nusselt number as a function of the different parameters $\operatorname{Pr}=10$ (first row), $\operatorname{Pr}=100$ (second row), $\operatorname{Pr}=10^{3}$ (third row)

\section{CONCLUSION}

From the above study, the two dimensional steady state natural convection of Ostwald-de waele pseudoplastic fluid in a gap formed by an inner grooved cylinder puts concentrically into its outer one investigated numerically. Effects of the parameters Prandtl, Rayleigh numbers, flow index $\mathrm{n}$ and the grooves number on the flow patterns and the heat transfer in the gap have been reported.

The simulation results revealed that the Nusselt number increases with increasing the number of Rayleigh for both Newtonian and pseudoplastic fluids while the increasing of Prandtl number causes a growth in the heat transfer for pseudoplastic fluids only. The number of grooves plays an important role in this study, it is shown that the smooth cylinder has the highest heat transfer rate, by adding the grooves the Nusselt number decreases until it reaches its minimum at the cylinder of 16 grooves. This latter one can harshly preserve the heat inside it to play the role of an insulator.

\section{REFERENCES}

[1] Acrivos, A., Shah, M.J., Petersen, E.E. (1960). Momentum and Heat Transfer in Laminar BoundaryLayer Flows of non-Newtonian Fluids Past External Surface. American Institute of Chemical Engineers AIChE, 6 (2): 312- 317.

[2] Emery, A.F., Chi, H.W., Dale, J.D. (1971). Free convection through vertical plane layers of nonNewtonian Power-law fluids, Journal of Heat Transfer, 93 (2): 164-171.

[3] Ozoe, H., Churchill, S.W. (1972). Hydrodynamic stability and natural convection in Ostwald-de Waele and Ellis fluids: the development of a numerical solution, AIChE, 18 (6): 1196-1207.

[4] Chenand, T.Y.W., Wollersheim, D.E. (1973). Free convection at a vertical plate with uniform flux condition in non-Newtonian Power-law fluids, Journal of Heat Transfer, 95 (1): 123-124.

[5] Hartnett, J.P., Kostic, M. (1985). Heat Transfer to a Viscoelastic Fluid in Laminar Flow Through a Rectangular Channel, Int. J. Heat Mass Transfer, 28 (6): 1147- 1155.

[6] Xie, C., Hartnett, J.P. (1992). Influence of Rheology on Laminar Heat Transfer to Viscoelastic Fluids in a Rectangular Channel, Ind. Eng. Chem. Res, 31: 727732.
[7] Patel, N., Ingham, D.B. (1994). Analytic Solutions for the Mixed Convection Flow of Non- Newtonian Fluids in Parallel Plate Ducts, Int. Comm. Heat Mass Transfer, 21(1): 75-84.

[8] Pericleous, K.A., (1994). Heat Transfer in Differentially Heated Non-Newtonian Cavities, Int. J. Numer. Meth. Heat Fluid Flow, 4 (3): 229-248.

[9] Fujii, F., Miyatake, O., Fujii, M., Tanaka, H. Murakami, K. (1973). Natural Convective Heat Transfer from a Vertical Isothermal Surface to a NonNewtonian Sutterby Fluid, Int. J. Heat Mass Transfer, 16 (12): 2177-2187.

[10] Ng, M.L., Hartnett, J.P. (1986). Natural convection in power law fluids, Int. Comm. Heat Mass Transfer, 13 (1): 115-120.

[11] Haq, S., Kleinstreuer, C., Mulligan, J.C. (1988). Transient free convection of a non Newtonian fluid along a vertical wall, Journal of Heat Transfer, 110 (3): 604-607.

[12] Leung, W.H., Hollands, K.G.T., Brunger, A.P. (1998). On a physically-realizable Benchmark problem in internal natural convection, Int. J. Heat Mass Transfer 41 (23): 3817-3828.

[13] Pittman, J.F.T., Richardson, J.F., Sherrard, C.P. (1999). An experimental study of heat transfer by laminar natural convection between an electricallyheated vertical plate and both Newtonian and nonNewtonian fluids, Int. J. Heat Mass Transfer, 42 (4): 657-671.

[14] Ohta, M., Akiyoshi, M., Obata, E. (2002). A numerical study on natural convective heat transfer of pseudoplastic fluids in a square cavity, Numer. Heat Transfer A, 41 (4): 357-372.

[15] Park, H.M., Ryu, D.H. (2001). Rayleigh-Bénard convection of viscoelastic fluids in finite domains, J. Non-Newt. Fluid Mech, 98 (2-3): 169-184.

[16] Inaba, H., Daib, C., Horibe, A. (2003). Natural convection heat transfer of micro-emulsion phasechange material slurry in rectangular cavities heated from below and cooled from above, Int. J. Heat Mass Transfer, 46 (23): 4427-4438.

[17] Lamsaadi, M., Naïmi, M., Hasnaoui, M. (2005). Natural convection of non-Newtonian power law fluids in a shallow horizontal rectangular cavity uniformly heated from below, Heat Mass Transfer, 41: 239-249.

[18] Lamsaadi, M., Naïmi, M., Hasnaoui, M., Mamou, M. (2006). Natural convection in a vertical rectangular cavity filled with a non-Newtonian power law fluid and subjected to a horizontal temperature gradient, Numer. Heat Transfer Part A, 49 (10): 969990. 
[19] Lamsaadi, M., Naïmi, M., Hasnaoui, M. (2006). Natural convection heat transfer in shallow horizontal rectangular enclosures uniformly heated from the side and filled with non-Newtonian power law fluids, Energy Convers. Manage, 47 (15-16): 2535-2551.

[20] Khezzar, L., Signiner, D., Vinogradov, I. (2011). Natural convection of power law fluids in inclined cavities, International Journal of Thermal Science, 53: 8-17.

[21] Barth, W.L., Carey, G.F. (2006). On a naturalconvection benchmark problem in non-Newtonian fluids, Numer. Heat Transfer Part B, 50 (3): 193-216.

[22] Solomatov, V., Barr, A. C. (2006). Onset of convection in fluids with strongly temperaturedependent power-law viscosity, Phys. Earth Planet. Inter, 155 (1-2): 140-145.

[23] Kaddiri, M., Naïmi, M., Raji, A., Hasnaoui, M. (2012). Rayleigh-Benard convection of non-Newtonian powerlaw fluids temperature-dependent viscosity, ISRN Thermodynamics, 614712 .

[24] Poole, R.J., Ridley, B.S. (2007). Development length requirements for fully-developed laminar pipe flow of inelastic non-Newtonian liquids, ASME J. Fluids Eng, 129 (10): 1281-1287.

[25] Srinivas, A.T., Bharti, R.P., Chhabra, R.P. (2009). Mixed convection heat transfer from a cylinder in power-law fluids: effect of aiding buoyancy, Ind. Eng. Chem. Res, 48 (21): 9735-9754.

[26] Balmforth, N.J., Rust, A.C. (2009). Weakly nonlinear viscoplastic convection, J. Non-Newt. Fluid Mech, 158 (1-3): 36-45.

[27] Albaalbaki, B., Khayat, R. E. (2011). Pattern selection in the thermal convection of non-Newtonian fluids. J. Fluid Mech, 668: 500-550.

[28] Turan, O., Sachdeva, A., Chakraborty, N., Poole, R.J. (2011). Laminar natural convection of power-law fluids in a square enclosure with differentially heated side walls subjected to constant wall temperatures, J. Non-Newt. Fluid Mech, 166 (17-18): 1049-1063.

[29] Turan, O., Sachdeva, A., Poole, R.J., Chakraborty, N. (2012). Laminar natural convection of power-law fluids in a square enclosure with differentially heated side walls subjected to constant wall heat flux, J. Heat Transfer Trans, ASME 134 (12): 1-15.

[30] Turan, O., Sachdeva, A., Poole, R.J., Chakraborty, N. (2013). Effects of aspect ratio on natural convection of power-law fluids in rectangular enclosures with differentially heated vertical sidewalls, Int. J. Heat Mass Transfer, 60: 722-738.

[31] Turan, O., Fotso-Choupe, F., Lai, J., Robert. J. Poole, Chakraborty, N. (2014). Boundary Condition Effects on Laminar Natural Convection of Power-Law Fluids in a Square Enclosure Heated from below with Differentially Heated Horizontal Walls, Industrial \& Engineering Chemistry Research, 53 (1): 456-473.

[32] Matin, M.H., Khan, W.A. (2013). Laminar Natural Convection of Non-Newtonian Power-Law Fluids between Concentric Circular Cylinders, Int. Comm. Heat Mass Transfer 43: 112-121.

[33] Zeraibi, N., Amoura, M., Benzaoui, A., Gareche, M. (2007). Numerical study of a thermodependent nonNewtonian fluid flow between vertical concentric cylinders, Int. Comm. Heat Mass Transfer, 34 (6): 740-752.

[34] Alloui, Z., Ben Khelifa, N., Beji, H., Vasseur, P., Guizani, A. (2013). The onset of convection of powerlaw fluids in a shallow cavity heated from below by a constant heat flux, J. Non-Newt. Fluid Mech, 196: 7082.

[35] Matin, M.H., Pop, I., Khanchezar, S. (2013). Natural convection of power-law fluid between two-square eccentric duct annuli, J. Non-Newt. Fluid Mech, 197: 11-23.

[36] Yigit, S., Graham, T., Robert J. Poole., Chakraborty, N. (2016). Numerical investigation of steady-state laminar natural convection of power-law fluids in square cross-sectioned cylindrical annular cavity with differentially-heated vertical walls, Int. J. Numerical Methods for Heat \& Fluid Flow, 26 (1): 85-107.

[37] Gangawane, K.M., Manikandan, B. (2017). Laminar natural convection characteristics in an enclosure with heated hexagonal block for non-Newtonian power law fluids, Chinese J. of Chemical Engineering, 25(5): 555-571.

\section{NOMECLATURE}

$\begin{array}{ll}\mathrm{C}_{\mathrm{P}} & \text { Specific heat capacity, } \mathrm{J} . \mathrm{kg}^{-1} \cdot \mathrm{K}^{-1} \\ \mathrm{~g} & \text { Gravitational acceleration, } \mathrm{m} \cdot \mathrm{s}^{-2} \\ \mathrm{~h} & \text { Heat transfer coefficient, W. } \mathrm{m}^{-2} \cdot \mathrm{K}^{-1} \\ \mathrm{k} & \text { Thermal conductivity, W. } \mathrm{m}^{-1} \cdot \mathrm{K}^{-1} \\ \mathrm{~K} & \text { Consistency index of the power-law, Pa.s } \\ \mathrm{L} & \text { Characteristic Length, } \mathrm{m} \\ \mathrm{n} & \text { Power law index } \\ \mathrm{Nu} & \text { Nusselt number } \\ \mathrm{P} & \text { Pressure, Pa } \\ \mathrm{Pr} & \text { Prandtl number } \\ \mathrm{Ra} & \text { Rayleigh number } \\ \mathrm{R}_{\mathrm{i}} & \text { Radius of the inner cylinder, } \mathrm{m} \\ \mathrm{R}_{\mathrm{o}} & \text { Radius of the outer cylinder, } \mathrm{m} \\ \mathrm{RR} & \text { Radius ratio } \\ \mathrm{T} & \text { Temperature, }{ }^{\circ} \mathrm{K} \\ \mathrm{T}_{\mathrm{h}} & \text { Temperature of the inner cylinder, }{ }^{\circ} \mathrm{K} \\ \mathrm{T}_{\mathrm{c}} & \text { Temperature of the outer cylinder, }{ }^{\circ} \mathrm{K} \\ \mathrm{u}, \mathrm{v} & \text { Radial and tangential velocities, } \mathrm{m} \cdot \mathrm{s}^{-1} \\ \mathrm{x}, \mathrm{y} & \text { Cartesian coordinates }\end{array}$

\section{Greek symbols}

$\begin{array}{ll}\alpha & \text { thermal diffusivity, } \mathrm{m}^{2} \cdot \mathrm{s}^{-1} \\ \beta & \text { thermal expansion coefficient, } \mathrm{K}^{-1} \\ \gamma & \text { Rate of strain tensor, } \mathrm{s}^{-1} \\ \Delta \mathrm{T} & \begin{array}{l}\text { Difference between hot and cold } \\ \text { temperatures, }{ }^{\circ} \mathrm{K}\end{array} \\ \theta & \begin{array}{l}\text { Dimensionless temperature } \\ \text { dynamic viscosity, } \mathrm{kg} \cdot \mathrm{m}^{-1} \cdot \mathrm{s}^{-1}\end{array} \\ \mu & \text { Density, kg. } \mathrm{m}^{-3} \\ \phi & \text { Orientation angle, }{ }^{\circ}\end{array}$

\section{Subscripts}

nom Nominal value

char Characteristic 